NASA/TM-2004-213051

\title{
Tensile Creep Fracture of Polycrystalline Near-Stoichiometric NiAl
}

Sai V. Raj

Glenn Research Center, Cleveland, Ohio 
Since its founding, NASA has been dedicated to the advancement of aeronautics and space science. The NASA Scientific and Technical Information (STI) Program Office plays a key part in helping NASA maintain this important role.

The NASA STI Program Office is operated by Langley Research Center, the Lead Center for NASA's scientific and technical information. The NASA STI Program Office provides access to the NASA STI Database, the largest collection of aeronautical and space science STI in the world. The Program Office is also NASA's institutional mechanism for disseminating the results of its research and development activities. These results are published by NASA in the NASA STI Report Series, which includes the following report types:

- $\quad$ TECHNICAL PUBLICATION. Reports of completed research or a major significant phase of research that present the results of NASA programs and include extensive data or theoretical analysis. Includes compilations of significant scientific and technical data and information deemed to be of continuing reference value. NASA's counterpart of peerreviewed formal professional papers but has less stringent limitations on manuscript length and extent of graphic presentations.

- TECHNICAL MEMORANDUM. Scientific and technical findings that are preliminary or of specialized interest, e.g., quick release reports, working papers, and bibliographies that contain minimal annotation. Does not contain extensive analysis.

- CONTRACTOR REPORT. Scientific and technical findings by NASA-sponsored contractors and grantees.
- CONFERENCE PUBLICATION. Collected papers from scientific and technical conferences, symposia, seminars, or other meetings sponsored or cosponsored by NASA.

- SPECIAL PUBLICATION. Scientific, technical, or historical information from NASA programs, projects, and missions, often concerned with subjects having substantial public interest.

- TECHNICAL TRANSLATION. Englishlanguage translations of foreign scientific and technical material pertinent to NASA's mission.

Specialized services that complement the STI Program Office's diverse offerings include creating custom thesauri, building customized databases, organizing and publishing research results ... even providing videos.

For more information about the NASA STI Program Office, see the following:

- Access the NASA STI Program Home Page at http://www.sti.nasa.gov

- E-mail your question via the Internet to help@sti.nasa.gov

- Fax your question to the NASA Access Help Desk at 301-621-0134

- Telephone the NASA Access Help Desk at 301-621-0390

- Write to:

NASA Access Help Desk

NASA Center for AeroSpace Information 7121 Standard Drive

Hanover, MD 21076 
NASA/TM-2004-213051

\section{Tensile Creep Fracture of Polycrystalline Near-Stoichiometric NiAl}

Sai V. Raj

Glenn Research Center, Cleveland, Ohio

National Aeronautics and

Space Administration

Glenn Research Center

May 2004 


\section{Acknowledgments}

The author acknowledges the help received from Mr. Peter Eichele and Mr. Thomas Monyhan in conducting the tensile creep tests. He also thanks Mr. James Smith for conducting the SEM observations. Partial financial support for this research was received from the Wright-Patterson Air Force Base, and this aid is gratefully acknowledged.

This work was sponsored by the Low Emissions Alternative

Power Project of the Vehicle Systems Program at the NASA Glenn Research Center.

Available from

NASA Center for Aerospace Information 7121 Standard Drive

Hanover, MD 21076
National Technical Information Service 5285 Port Royal Road Springfield, VA 22100 


\title{
Tensile Creep Fracture of Polycrystalline Near-Stoichiometric NiAl
}

\author{
S.V. Raj \\ National Aeronautics and Space Administration \\ Glenn Research Center \\ Cleveland, Ohio 44135
}

\begin{abstract}
Tensile creep fracture behavior of polycrystalline near-stoichiometric NiAl has been studied between 700 and $1200 \mathrm{~K}$ under initial applied stresses varying between 10 and $200 \mathrm{MPa}$. The stress exponents for fracture varied between 5.0 and 10.7 while the activation energy for fracture was $250 \pm 22 \mathrm{~kJ} \mathrm{~mol}^{-1}$. The fracture life was inversely proportional to the secondary creep rate in accordance with the Monkman-Grant relation although there was extensive scatter in the data. This observation suggests that the fracture life for near-stoichiometric NiAl was influenced by creep under these stress and temperature conditions. Several different fracture morphologies were observed. Transgranular ductile cleavage fracture occurs at $700 \mathrm{~K}$ and at the higher stresses at $800 \mathrm{~K}$. The fracture mode transitions to transgranular creep fracture at 900 and $1000 \mathrm{~K}$ and at lower stresses at $800 \mathrm{~K}$, while plastic rupture and grain boundary cavitation occur at 1100 and $1200 \mathrm{~K}$. An experimental fracture mechanism map is constructed for near-stoichiometric NiAl.
\end{abstract}

\section{Introduction}

Binary NiAl ${ }^{*}$ with a B2 crystal structure possesses an attractive combination of oxidation, physical and thermal properties which make it a potentially useful material for fabricating turbine blades to withstand temperatures above $1200 \mathrm{~K}$. As a result, a considerable amount of research has been conducted on developing NiAl-based alloys for use in gas-turbine aircraft engines over the last several decades [1-18]. However, most of these data have been obtained under compression loading with virtually no detailed information being available on the tensile creep of NiAl until recently [18]. Thus, little is known about the creep rupture properties of NiAl.

The objectives of this paper are to report the creep rupture behavior of NiAl with a view of constructing an experimental fracture mechanism map. The development of this map can provide important insights on the nature of the fracture processes dominant in this alloy under different stress and temperature conditions, and aid in alloy and engineering design. These results compliment the long term tensile creep data presented in an earlier paper [18].

\section{Experimental Materials and Procedures}

Details of the experimental materials and procedures have been previously described [18], and only a brief description is presented here. The materials used in this study were obtained from two heats of induction melted NiAl. The ingots were vacuum-sealed in mild steel cans and extruded at $1400 \mathrm{~K}$ using

\footnotetext{
${ }^{*}$ Unless otherwise stated, all compositions are reported in at.\% in this paper.
} 
Table 1.-Chemical composition in at.\% and the initial grain sizes of the two extruded NiAl rods [18].

\begin{tabular}{|c|c|c|c|c|c|c|c|}
\hline $\begin{array}{c}\text { Extrusion } \\
\text { I.D. }\end{array}$ & $\begin{array}{c}\text { Extrusion } \\
\text { conditions }\end{array}$ & $\mathrm{Al}$ & $\mathrm{C}$ & $\mathrm{N}$ & $\mathrm{Ni}$ & $\mathrm{O}$ & $\mathrm{d}(\mu \mathrm{m})$ \\
\hline L 3175 & $\begin{array}{c}1400 \mathrm{~K} ; \\
16: 1\end{array}$ & 49.8 & 0.0090 & 0.0005 & 50.2 & 0.0110 & $38.7 \pm 2.5$ \\
\hline L 3176 & $\begin{array}{c}1400 \mathrm{~K} ; \\
20: 1\end{array}$ & 50.6 & 0.0270 & 0.0010 & 49.4 & 0.0120 & $38.6 \pm 2.3$ \\
\hline
\end{tabular}

ratios of 16:1 and 20:1. The compositions and grain sizes, $d$, of the two batches of material are given in table 1, where it is evident that the choice of these two extrusion ratios did not significantly alter the final grain size of the extruded rods. The longitudinal and transverse grain sizes of the extruded rods revealed that the grains were equiaxed and completely recrystallized [18]. Smooth button-head tensile specimens having nominal gage lengths $30.5 \mathrm{~mm}$ and gage diameters $3.0 \mathrm{~mm}$ were centerless ground from the extruded rods. The machined surfaces were removed by electropolishing the specimens in a $10 \%$ perchloric acid- $90 \%$ methanol bath prior to testing, and the gage length and gage diameter of each specimen were carefully measured under a traveling microscope. Constant load tensile creep tests were conducted in lever arm machines at absolute temperatures, $T$, between 700 and $1200 \mathrm{~K}$ under initial applied stresses, $S_{a}$, varying between 10 and $200 \mathrm{MPa}$. Three thermocouples were attached along the gage length of the specimen and the accuracy of temperature control and the temperature gradient along the gage length were $\pm 1 \mathrm{~K}$. The specimen load train was allowed to stabilize at temperature for at least $1 \mathrm{~h}$ prior to loading. The elongation of the specimen was measured by attaching an extensometer to the top and bottom couplings in most of the tests, where the displacement of the extensometer heads was measured either by a linear variable displacement transformer (LVDT) or a super linear variable capacitance (SLVC) transducer. The elongation and temperature data were continuously monitored by a computerized data acquisition system. Most of the specimens were tested until rupture except in the case of a few very long term tests, which were terminated prior to fracture. ${ }^{\dagger}$ The gage lengths and gage diameters of either the two halves of the ruptured specimen or the entire unbroken specimen were measured under a traveling microscope in order to evaluate either the rupture ductility, $\varepsilon_{f}$, or the final deformation strain, respectively, and in the case of ruptured specimens, the reduction in area (R.A.).

The characterization of the fracture surfaces was conducted in a scanning electron microscope (SEM). The specimens were longitudinally sectioned and polished parallel to the stress axis for viewing under an optical microscope.

\section{Results}

\section{Stress Dependence of the Rupture Life}

Figure 1 shows the variation of the rupture life, $t_{f}$, with $S_{a}$ between 700 and $1200 \mathrm{~K}$, where the solid lines represent the linear regression fits to the data. The corresponding variation of the true secondary creep rate, $\dot{\varepsilon}$, with true stress, $\sigma$, is reported elsewhere [18]. The arrows associated with some of the data indicate that these tests were stopped prior to rupture so that only the total test time is reported. Despite the fact that these data do not represent actual failure times, they were included in the regression analysis if they appeared to fall sufficiently close to the line extrapolated from data obtained on ruptured

\footnotetext{
${ }^{\dagger}$ The data reported in this paper for these unruptured specimens represent the total test time.
} 


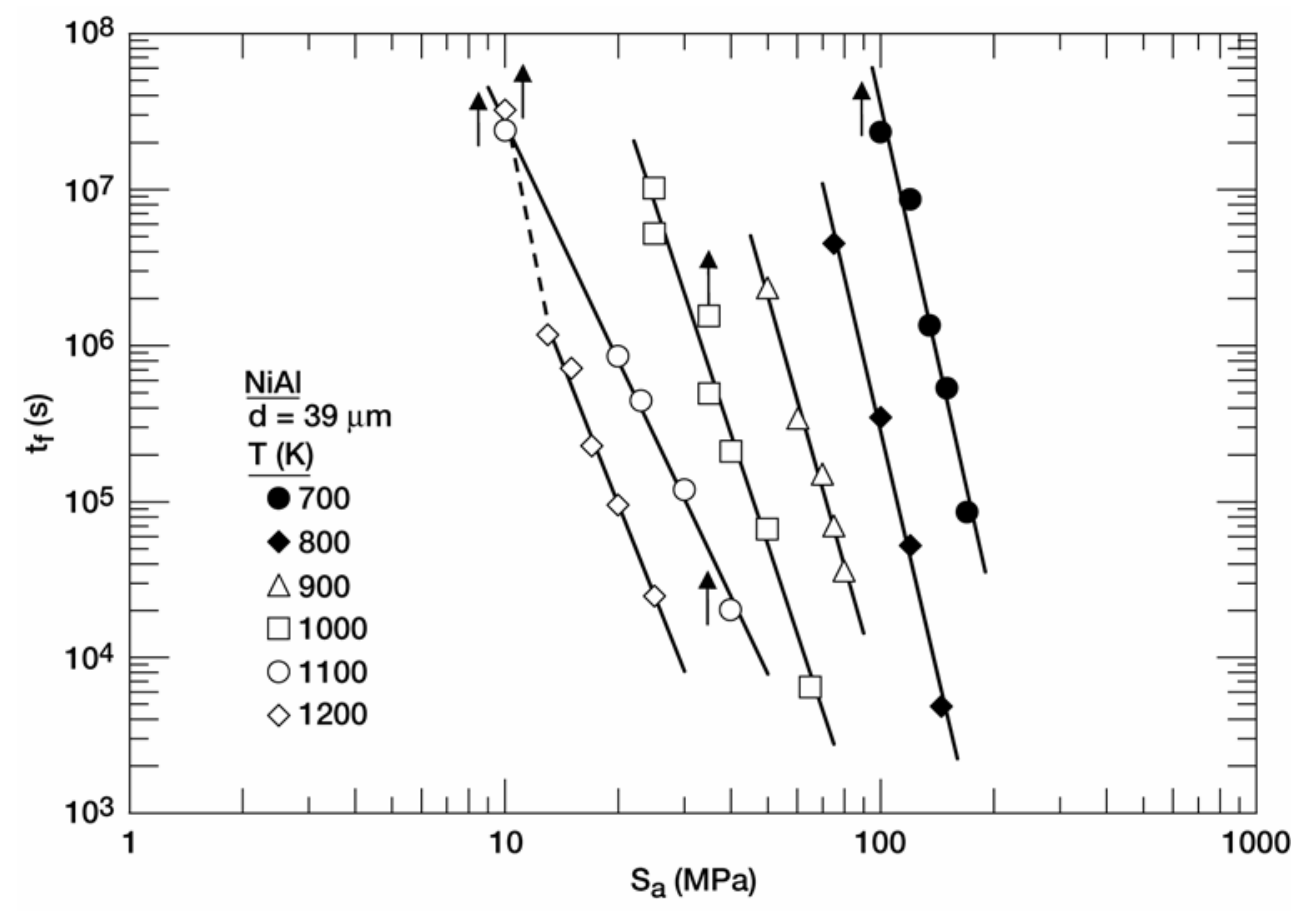

Figure 1.-Variation of the fracture life with initial applied stress for near-stoichiometric $\mathrm{NiAl}$ between 700 and $1200 \mathrm{~K}$. Datum points associated with arrows indicate the total test time for specimens that were interrupted prior to fracture.

Table 2.- Comparison of the values of $C, q$, and $R_{d}^{2}$ determined from creep rupture data on $\mathrm{NiAl}$ with corresponding creep stress exponents reported under identical engineering stress and temperature conditions [18].

\begin{tabular}{|c|c|c|c|c|c|c|}
\hline $\mathrm{T}(\mathrm{K})$ & $S_{a}(\mathrm{MPa})$ & $q$ & $C\left(\mathrm{MPa}^{q} \bullet \mathrm{s}\right)$ & $R_{d}^{2}$ & $\begin{array}{c}\text { Sample } \\
\text { size }\end{array}$ & $n$ \\
\hline 700 & 100 to 170 & 10.7 & $1.1 \times 10^{29}$ & 0.969 & 5 & 13.9 \\
\hline 800 & 75 to 145 & 10.3 & $1.0 \times 10^{26}$ & 0.993 & 4 & 8.7 \\
\hline 900 & 50.0 to 80.0 & 8.5 & $5.1 \times 10^{20}$ & 0.987 & 5 & 13.2 \\
\hline 1000 & 25.0 to 35.0 & 7.3 & $1.2 \times 10^{17}$ & 0.971 & 7 & 5.1 \\
& 35.0 to 65.0 & & & & & 12.3 \\
\hline 1100 & 10.0 to 39.8 & 5.1 & $3.0 \times 10^{12}$ & 0.997 & 5 & 6.1 \\
\hline 1200 & 13.0 to 25.0 & 6.1 & $8.1 \times 10^{12}$ & 0.990 & 5 & 4.9 \\
\hline
\end{tabular}

specimens. It was felt that this procedure would improve the predictive capability of the regressed line at the lower stresses where data were limited. As shown in figure 1, the datum point obtained at $1200 \mathrm{~K}$ under an initial stress of $10 \mathrm{MPa}$ appeared to deviate substantially from other data obtained at this temperature, and therefore, it was excluded from the regression analysis. It is noted that the secondary creep rate for this specimen was observed to be much lower than the predicted trend in the $\dot{\varepsilon}-\sigma$ plot [18]. The rupture life exhibits a power-law dependency on the applied stress through

$$
t_{f}=C\left(S_{a}\right)^{-q}
$$

where $C$ is a microstructure and temperature dependent constant and $q$ is the creep fracture stress exponent. The magnitudes of $C$ and $q$ from the linear regression analysis are tabulated in table 2 , where 
$R_{d}^{2}$ is the coefficient of determination. The values of $C$ and $q$ vary from $1.1 \times 10^{29} \mathrm{MPa}^{10.7} \bullet \mathrm{s}$ and 10.7 , respectively, at $700 \mathrm{~K}$ to $8.1 \times 10^{12} \mathrm{MPa}^{6.1} \cdot \mathrm{s}$ and 6.1 , respectively, at $1200 \mathrm{~K}$. For comparison, the corresponding values of the stress exponent, $n$, for creep varied from 13.9 at $700 \mathrm{~K}$ to 4.9 at $1200 \mathrm{~K}$ (table 2) [18].

\section{Temperature Dependence of Rupture Life}

The true activation energy for fracture, $Q_{f}$, was determined from the slopes of Arrhenius plots of $t_{f} E / T$ against $1 / T$, where $E$ is the Young's modulus, based on the observed rupture lives at constant values of the applied stress varying between 20 and $120 \mathrm{MPa}$ (fig. 2). The temperature dependence of $E$ was determined from the equation

$$
E=2.37 \times 10^{5}-51 T(\mathrm{MPa})
$$

obtained from a linear regression fit to experimental data [19]. Although $Q_{f}$ varied between about 203 and $292 \mathrm{~kJ} \mathrm{~mol}^{-1}$, it exhibited only a weak dependence on the applied stress (fig. 3). The horizontal line with $Q_{f} \approx 250 \pm 22 \mathrm{~kJ} \mathrm{~mol}^{-1}$ shown in figure 3 represents the mean value for all the data. This value is somewhat less than the experimental activation energies for lattice self-diffusion of $\mathrm{Ni}, Q^{*}{ }_{N i}$, in nearstoichiometric NiAl based on tracer diffusion measurements, which have been determined to be about 305 [20] and $290 \mathrm{~kJ} \mathrm{~mol}^{-1}$ [21]. The vertical broken lines demarcate the four creep deformation regimes reported earlier for this material [18]. The data shown in figure 3 primarily correspond to the deformation regimes II and III, where the activation energy for creep, $Q_{c}$, was about 400 and $250 \mathrm{~kJ} \mathrm{~mol}^{-1}$, respectively. The ratio $Q_{c} / Q_{f}$ at each value of applied stress is also plotted in figure 3, where it is evident

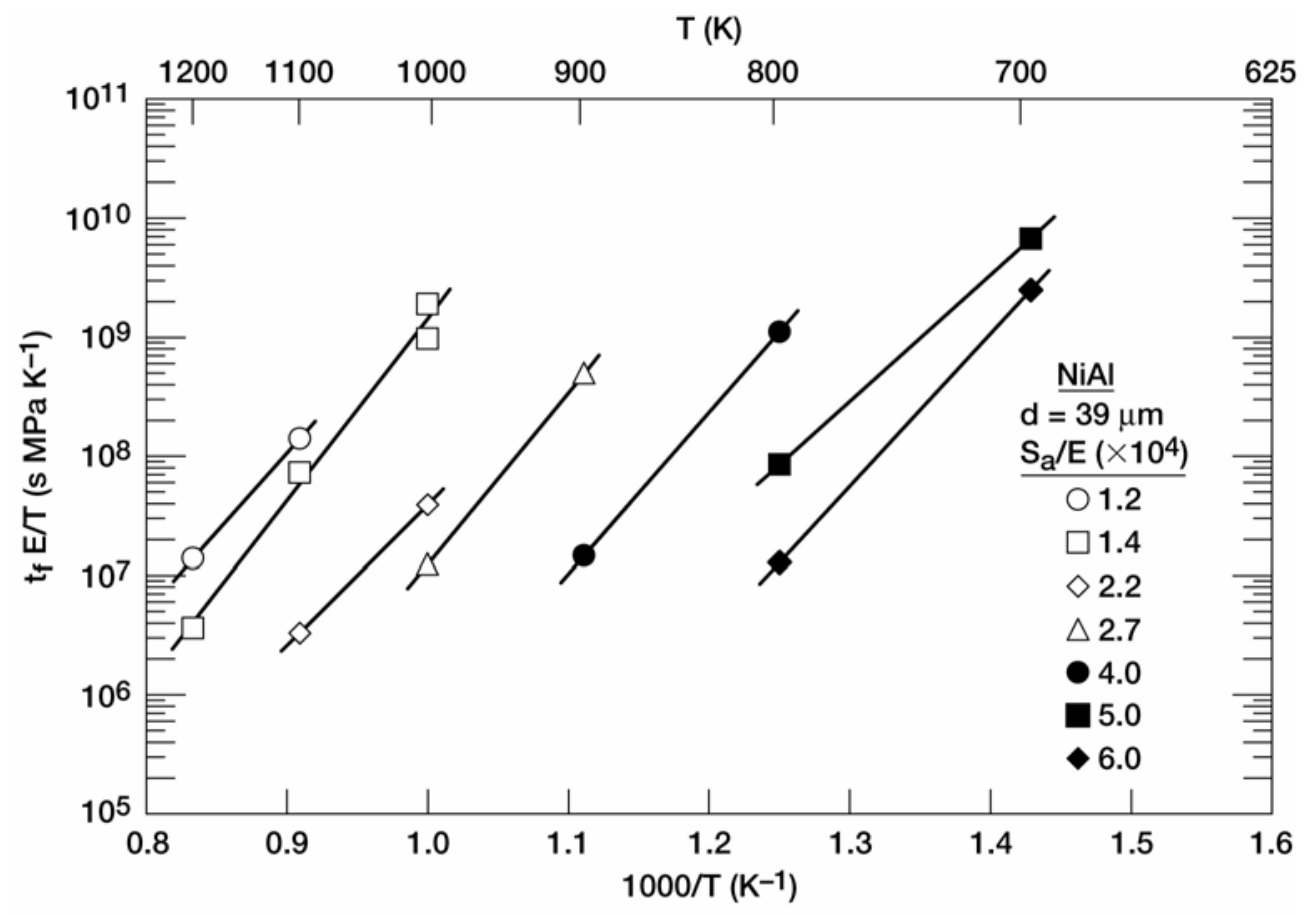

Figure 2.-Arrhenius plots for near-stoichiometric NiAl for initial applied stresses varying between $21.1 \mathrm{MPa}\left(\mathrm{S}_{\mathrm{a}} / \mathrm{E} \sim 1.2 \times 10^{-4}\right)$ and $120 \mathrm{MPa}\left(\mathrm{S}_{\mathrm{a}} / \mathrm{E} \sim 6.0 \times 10^{-4}\right)$. The creep fracture life has been normalized by the absolute temperature and the Young' s modulus to be consistent with similar analyses for the secondary creep [18]. 


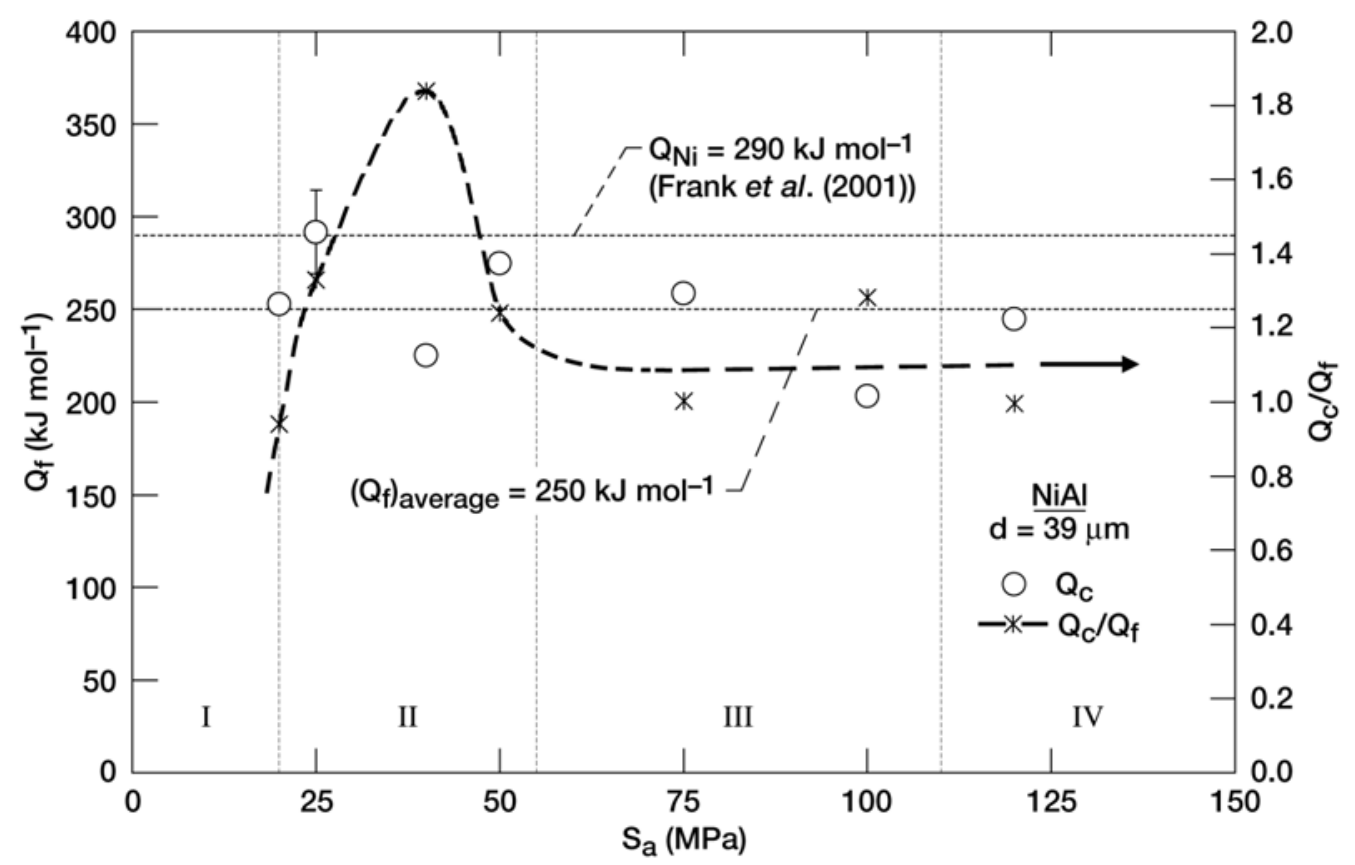

Figure 3.-True activation energy for creep fracture life versus initial applied stress for near-stoichiometric NiAl. The upper horizontal broken line represents the activation energy for lattice tracer diffusion of $\mathrm{Ni}$ reported by Frank et al. [21]. The lower horizontal broken line represents the average activation energy for fracture. The vertical broken lines demarcate the four creep regimes observed in near-stoichiometric $\mathrm{NiAl}$ [18].

that $Q_{c} / Q_{f}$ is as high as about 1.9 in creep regime II while being close 1.0 in regime III. An examination of figure 3 suggests that $Q_{f}$ is about $150 \mathrm{~kJ} \mathrm{~mol}^{-1}$ less than the measured value of $Q_{c}$ in regime II. However, the average value of $Q_{f}$ is in reasonably good agreement with the measured value of $Q_{c}$ in the creep regime III. These results suggest that the rate controlling mechanisms for creep and fracture are different in creep regime II while they appear to be similar in regime III.

\section{Monkman-Grant Plot and Creep Ductility}

Monkman and Grant (MG) [22] first demonstrated that there is a strong inverse correlation between creep rupture life and the secondary creep rate in pure metals and solid solution alloys. They showed that experimental data follow the relationship

$$
t_{f}=\frac{C^{*}}{\dot{\varepsilon}^{m}}
$$

where $m$ and $C^{*}$ are constants. The experimental values of $m$ and $C^{*}$ were observed to be 0.77 to 1.0 and 0.05 to 2.0, respectively, for several different metals and alloys [22-25]. In practice, equation (3) is often simplified to $t_{f} \dot{\varepsilon} \approx C_{M G}$, where $C_{M G}=C^{*}$ is known as the Monkman-Grant constant with $m=1$. The values of $C_{M G}$ vary between 1.8 and 38 for many metals and alloys [22]. The Monkman-Grant constant can be broadly interpreted as a simple measure of creep ductility since it ignores strain contributions from primary and tertiary creep [26,27]. Monkman and Grant [22] associated low values of $C_{M G}$ with intergranular fracture, where the secondary creep stage lasted much longer than the primary and the tertiary creep stages. However, high values of $C_{M G}$ were observed when the secondary creep stage was relatively small compared to the primary and tertiary creep stages and transgranular fracture was observed in these instances. 

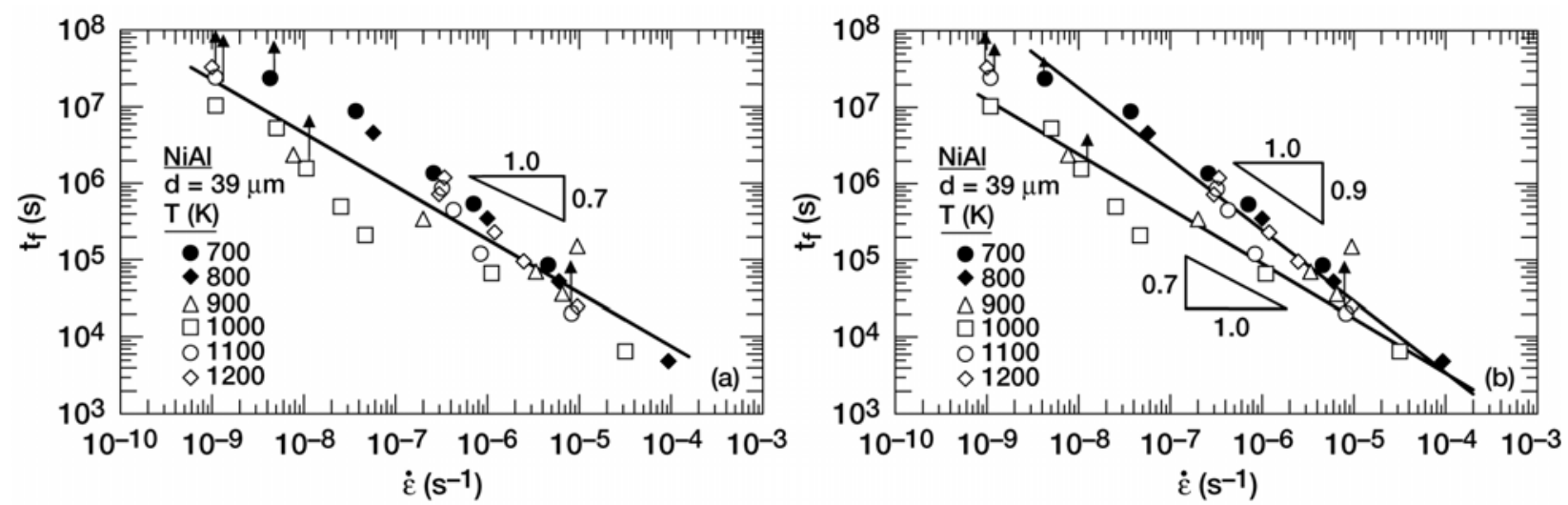

Figure 4.-Dependence of the creep fracture life on the secondary creep rate for near-stoichiometric NiAl between 700 and $1200 \mathrm{~K}$. Data for specimens that were interrupted prior to failure are associated with arrows.

Figure 4(a) shows the variation of $t_{f}$ against $\dot{\varepsilon}$. Once again, the arrows denote tests that were terminated prior to failure. In this case, a single regression line is used to represent all the data, where it is described by

$$
t_{f}=\frac{12.45}{\dot{\varepsilon}^{0.7}} \quad\left(R_{d}^{2}=0.86\right)
$$

Although the magnitude of $m$ given by equation (4) is consistent with other values reported in the literature, the value of $C^{*}$ is significantly higher than other observed data by one to two orders of magnitude [22-25]. Alternatively, the data shown in figure 4(a) are represented by two regression lines in figure 4(b), where they are described by

$$
\begin{aligned}
& t_{f}=\frac{0.68}{\dot{\varepsilon}^{0.9}} \quad\left(R_{d}^{2}=0.90\right) \\
& t_{f}=\frac{4.73}{\dot{\varepsilon}^{0.7}} \quad\left(R_{d}^{2}=0.96\right)
\end{aligned}
$$

These values of $C^{*}$ and $m$ given by equations (4b) and (4c) are more consistent with those reported in the literature. It is noted that equations (4b) and (4c) represent the data somewhat better than equation (4a) as indicated by the magnitudes of $R_{d}^{2}$. It is interesting to note that the data obtained at $1000 \mathrm{~K}$ lie predominantly on the plot described by equation (4c).

Figure 5 shows the temperature dependence of $C_{M G}$ and R.A. for the ruptured specimens along with the corresponding fitted polynomial curves, where $C_{M G}$ was derived from the product $t_{f} \dot{\varepsilon}$. The R.A. increases with increasing temperature from about $80 \%$ at $700 \mathrm{~K}$ to about $100 \%$ at $1200 \mathrm{~K}$ while the $C_{M G}-T$ plot exhibits a minimum at $1000 \mathrm{~K}$. The minimum and maximum values of $C_{M G}$ are represented by the two curves shown in figure 5 , which were determined from polynomial regression fits to the data with the exception of the single datum point for which $C_{M G} \approx 1.4$. The experimental values of $C_{M G}$ lie between 0.01 and 0.45 similar to those reported for pure metals and alloys [22]. 
Figure 6 shows the variation of the tensile ductility with fracture life. There is a large amount of scatter in the ductility when $t_{f}<35 \mathrm{~h}$ but the extent of scatter diminishes and becomes relatively small when $t_{f}>650 \mathrm{~h}$ as indicated by the two broken curves. It is noted that data obtained at and above $1000 \mathrm{~K}$ form the upper bound while those obtained at and below $1000 \mathrm{~K}$ form the lower bound when $t_{f}>35 \mathrm{~h}$. No distinctive temperature dependence can be discerned from the data. The fracture ductility varies between 48 and $115 \%$ for the stress and temperature conditions studied in this investigation. Despite the scatter, the lower and upper scatter curves shown in figure 6 suggest that the $\varepsilon_{f}-t_{f}$ plot exhibits ductility minima between 400 and $650 \mathrm{~h}$.

\section{Fracture Morphologies}

Despite the fact that the tensile ductility exceeded $40 \%$ for all the failed specimens irrespective of stress and temperature, visual and microstructural examination of the fractured samples revealed vastly different morphologies depending on stress and temperature. The microstructures of the observed specimens generally showed mixed modes of fracture. As indicated by Ashby [28], and Gandhi and Ashby [29], the fracture paths in many materials are quite sensitive to small changes in composition, inclusion or precipitate densities, texture, localized stress and temperature, which can complicate the interpretation of fracture microstructures. In addition, the fracture morphology can be influenced by fast fracture occurring during the final stages of tertiary creep. In this case, it is likely that the fracture surfaces of NiAl may show evidence of cleavage fracture. Thus, creep fracture surface morphologies of NiAl must be studied in conjunction with microstructural observations on longitudinally polished sections of the tested specimens. The present description is similar to the guidelines followed by Ashby et al. [28-32].

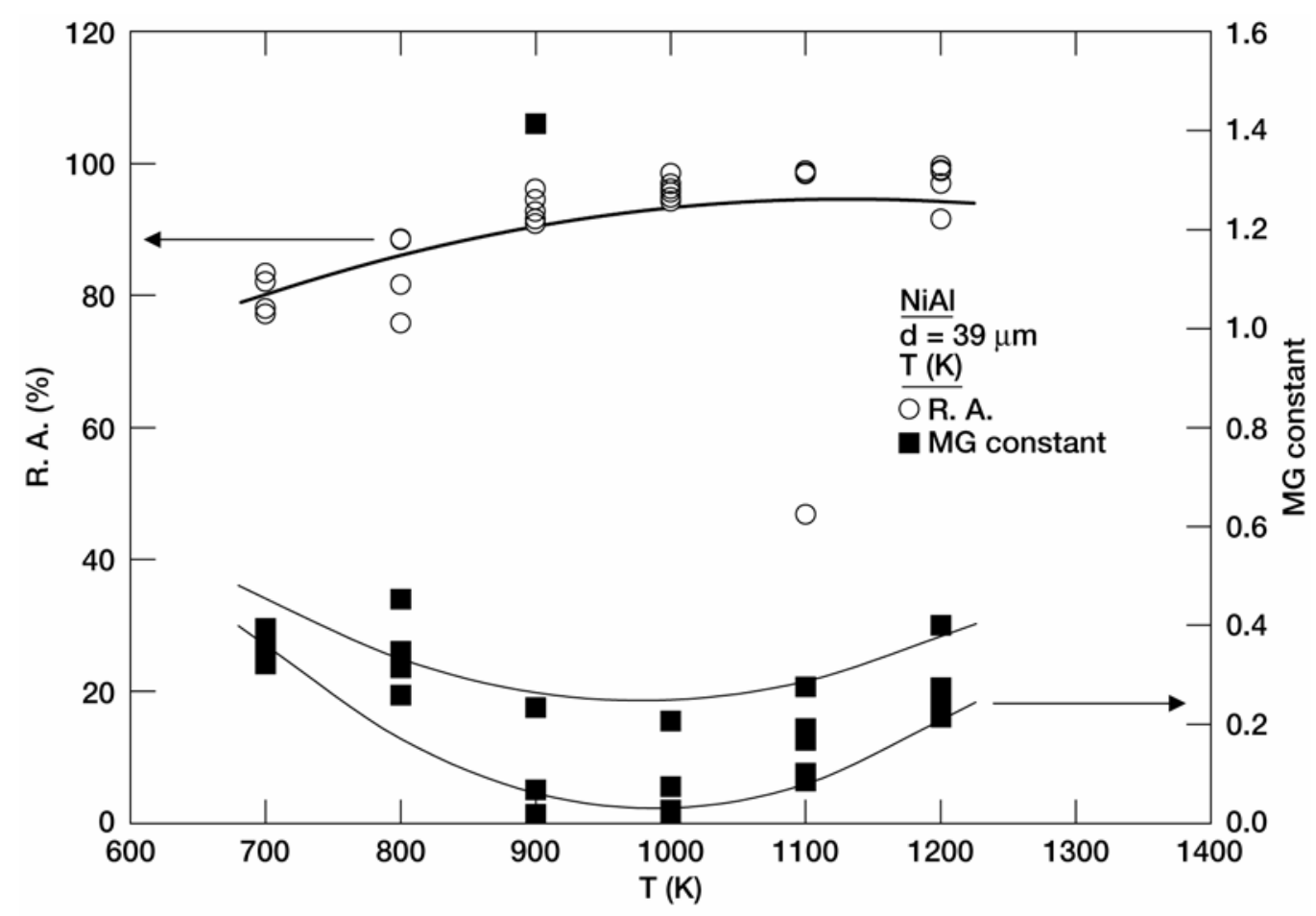

Figure 5.-Variations of the reduction in area (R.A.) and the Monkman-Grant constants with absolute temperature for near-stoichiometric NiAl. 


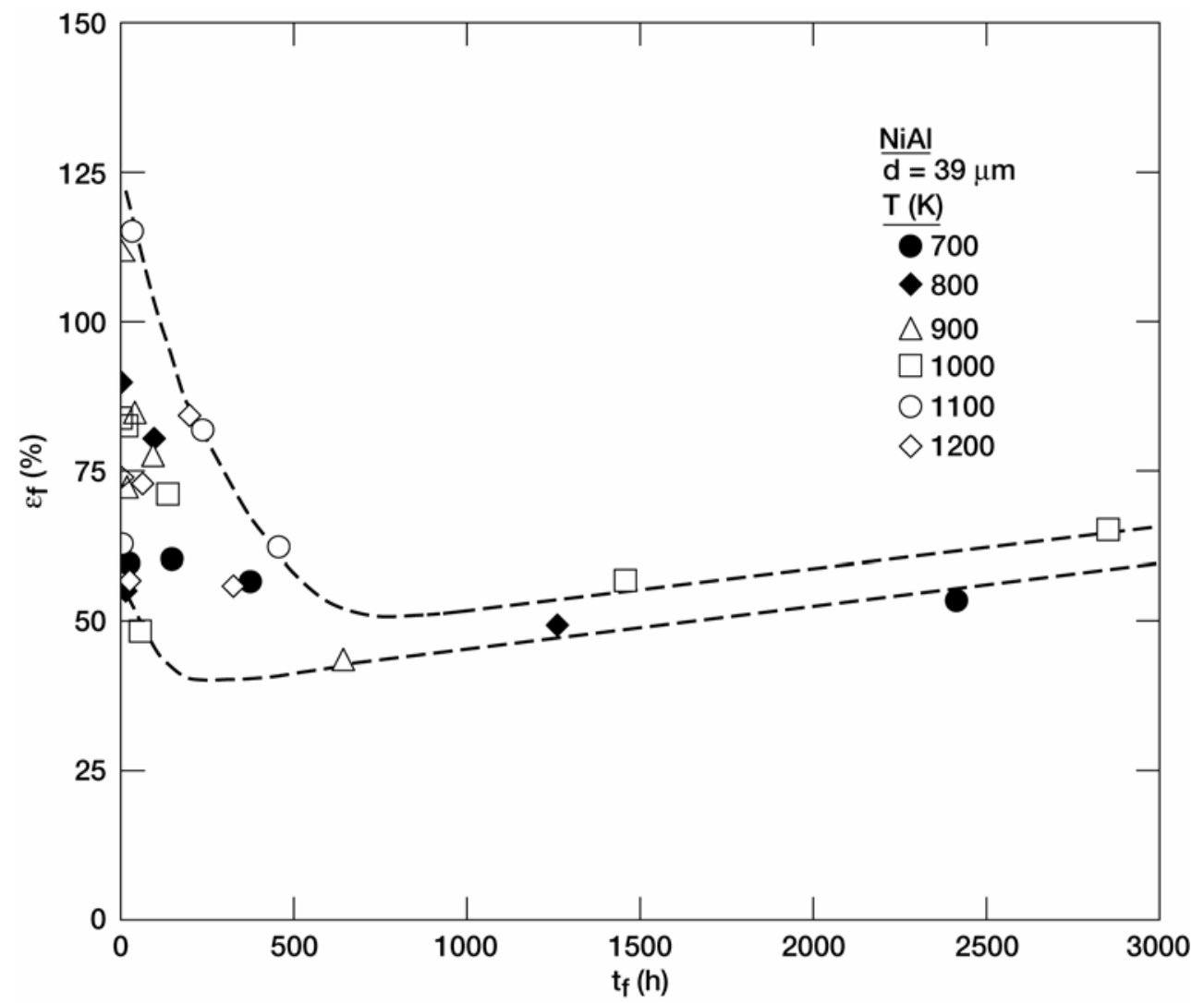

Figure 6.-Creep fracture ductility versus creep fracture life for near-stoichiometric NiAl between 700 and $1200 \mathrm{~K}$.

Figures 7(a) to (m) show the longitudinally polished fracture microstructures for specimens tested between 700 and $1200 \mathrm{~K}$ under applied stresses varying between 13 and $170 \mathrm{MPa}$. Specimens crept at $700 \mathrm{~K}$, and at the higher stresses at $800 \mathrm{~K}$, predominantly exhibited transgranular ductile cleavage fracture with severe grain deformation evident in the etched microstructures (fig. 8). Low magnification optical micrographs of the longitudinal specimen cross-sections revealed fracture surfaces approximately $90^{\circ}$ to the tensile axis with the occurrence of external necking (figs. 7(a)-(d)). The gage section was largely free of voids and cracks well outside the fracture region although elongated cavities, inclined to the stress axis, and crack were observed near the fracture zone in many specimens (figs. 9(a) and (b)).

The fracture morphologies at 900 and $1000 \mathrm{~K}$ showed a distinct transition towards a cup and cone ductile fracture mode (figs. 7(e)-(g)). Scanning electron micrographs showed the dimpled fracture characteristic of this failure mode (fig. 10). The fracture surfaces revealed the presence of intergranular and transgranular voids (figs. 11(a)-(c)), ${ }^{*}$ where some of these voids had undergone growth and coalescence (fig. 12). Observations on longitudinal polished microstructures of these specimens revealed a general absence of voids and cavities far away from the fracture zone although elongated cavities were observed close to the point of fracture. These fracture morphologies have been characterized as transgranular creep fracture in the literature [28,29,33-35].

\footnotetext{
* The cleavage morphologies observed in figures 11 and 12 are presumed to be due to fast fracture occurring in the final stages of tertiary creep. Therefore, they are not considered in the description of these fracture morphologies.
} 

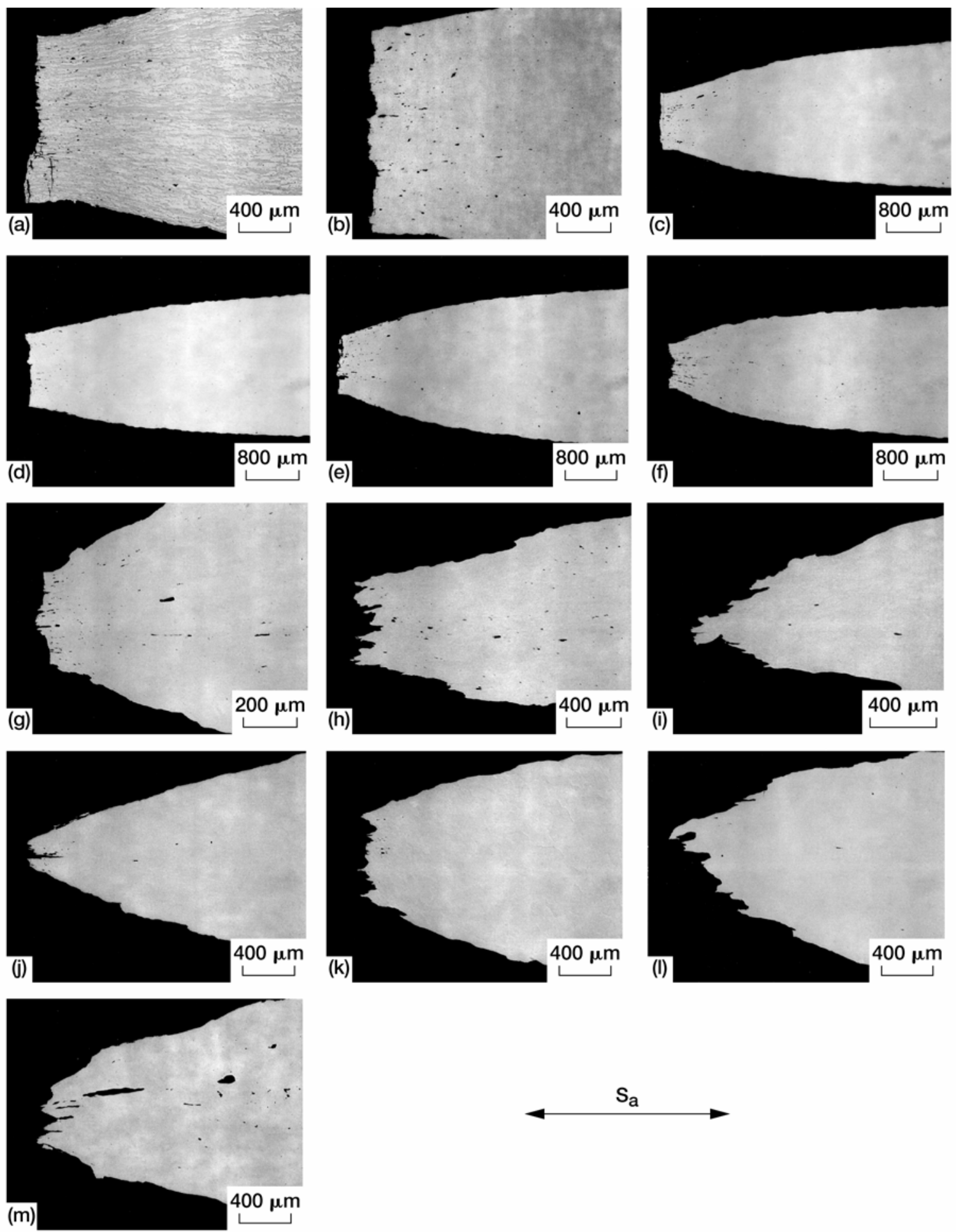

Figure 7.-Optical microstructures of as-polished longitudinal sections of specimens after creep fracture showing different failure modes under different initial applied stress and temperature conditions. The stress axes are parallel to the longitudinal axes of the specimens. (a) $\mathrm{T}=700 \mathrm{~K}, \mathrm{~S}_{\mathrm{a}}=120 \mathrm{MPa}, \mathrm{t}_{\mathrm{f}}=2413.6 \mathrm{~h}$;

(b) $\mathrm{T}=700 \mathrm{~K}, \mathrm{~S}_{\mathrm{a}}=170 \mathrm{MPa}, \mathrm{t}_{\mathrm{f}}=23.8 \mathrm{~h}$; (c) $\mathrm{T}=800 \mathrm{~K}, \mathrm{~S}_{\mathrm{a}}=75 \mathrm{MPa}, \mathrm{t}_{\mathrm{f}}=1260.7 \mathrm{~h}$; (d) T = 800 K, $\mathrm{S}_{\mathrm{a}}=100 \mathrm{MPa}$, $\mathrm{t}_{\mathrm{f}}=96.4 \mathrm{~h} ;(\mathrm{e}) \mathrm{T}=900 \mathrm{~K}, \mathrm{~S}_{\mathrm{a}}=50 \mathrm{MPa}, \mathrm{t}_{\mathrm{f}}=643.2 \mathrm{~h} ;(\mathrm{f}) \mathrm{T}=900 \mathrm{~K}, \mathrm{~S}_{\mathrm{a}}=80 \mathrm{MPa}, \mathrm{t}_{\mathrm{f}}=9.9 \mathrm{~h} ;(\mathrm{g}) \mathrm{T}=1000 \mathrm{~K}$, $\mathrm{S}_{\mathrm{a}}=25 \mathrm{MPa}, \mathrm{t}_{\mathrm{f}}=1458.2 \mathrm{~h}$; (h) $\mathrm{T}=1000 \mathrm{~K}, \mathrm{~S}_{\mathrm{a}}=50 \mathrm{MPa}, \mathrm{t}_{\mathrm{f}}=18.5 \mathrm{~h}$; (i) $\mathrm{T}=1100 \mathrm{~K}, \mathrm{~S}_{\mathrm{a}}=20 \mathrm{MPa}, \mathrm{t}_{\mathrm{f}}=237.6 \mathrm{~h}$; (j) $\mathrm{T}=1100 \mathrm{~K}, \mathrm{~S}_{\mathrm{a}}=23 \mathrm{MPa}, \mathrm{t}_{\mathrm{f}}=123.6 \mathrm{~h}$; (k) $\mathrm{T}=1200 \mathrm{~K}, \mathrm{~S}_{\mathrm{a}}=25 \mathrm{MPa}, \mathrm{t}_{\mathrm{f}}=6.9 \mathrm{~h}$; (I) $\mathrm{T}=1200 \mathrm{~K}, \mathrm{~S}_{\mathrm{a}}=20 \mathrm{MPa}$, $\mathrm{t}_{\mathrm{f}}=26.5 \mathrm{~h} ;(\mathrm{m}) \mathrm{T}=1200 \mathrm{~K}, \mathrm{~S}_{\mathrm{a}}=13 \mathrm{MPa}, \mathrm{t}_{\mathrm{f}}=326.6 \mathrm{~h}$. 


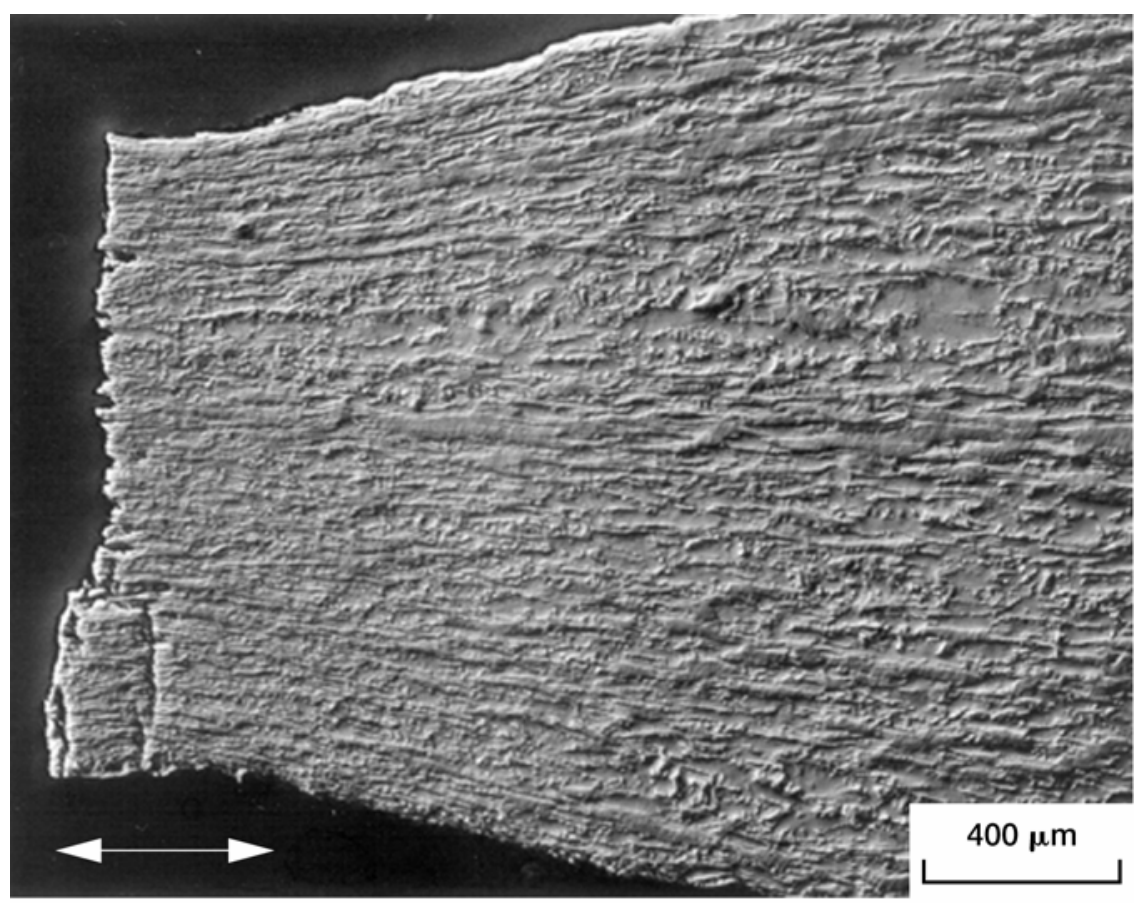

Figure 8.-Optical microstructure of the specimen crept at $700 \mathrm{~K}$ under an initial applied stress of $120 \mathrm{MPa}$ with a fracture life of $2413.6 \mathrm{~h}$ showing extensive grain deformation. The arrow denotes the stress axis.
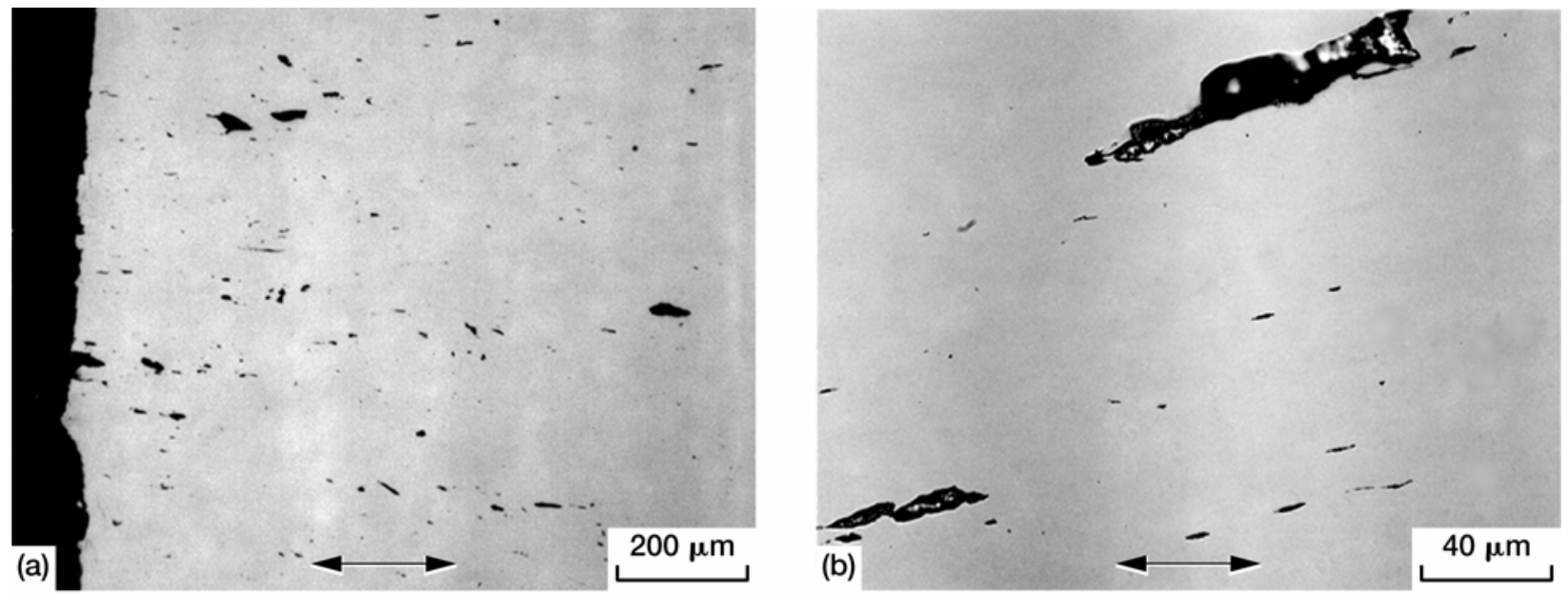

Figure 9.-Optical micrographs showing elongated cavities and cracks near the fractured ends of specimens tested at (a) $\mathrm{T}=700 \mathrm{~K}, \sigma=150 \mathrm{MPa}, \mathrm{t}_{\mathrm{f}}=148.6 \mathrm{~h}$, and (b) $\mathrm{T}=800 \mathrm{~K}, \sigma=75 \mathrm{MPa}, \mathrm{t}_{\mathrm{f}}=1260.7 \mathrm{~h}$. The arrows indicate the stress axes. 


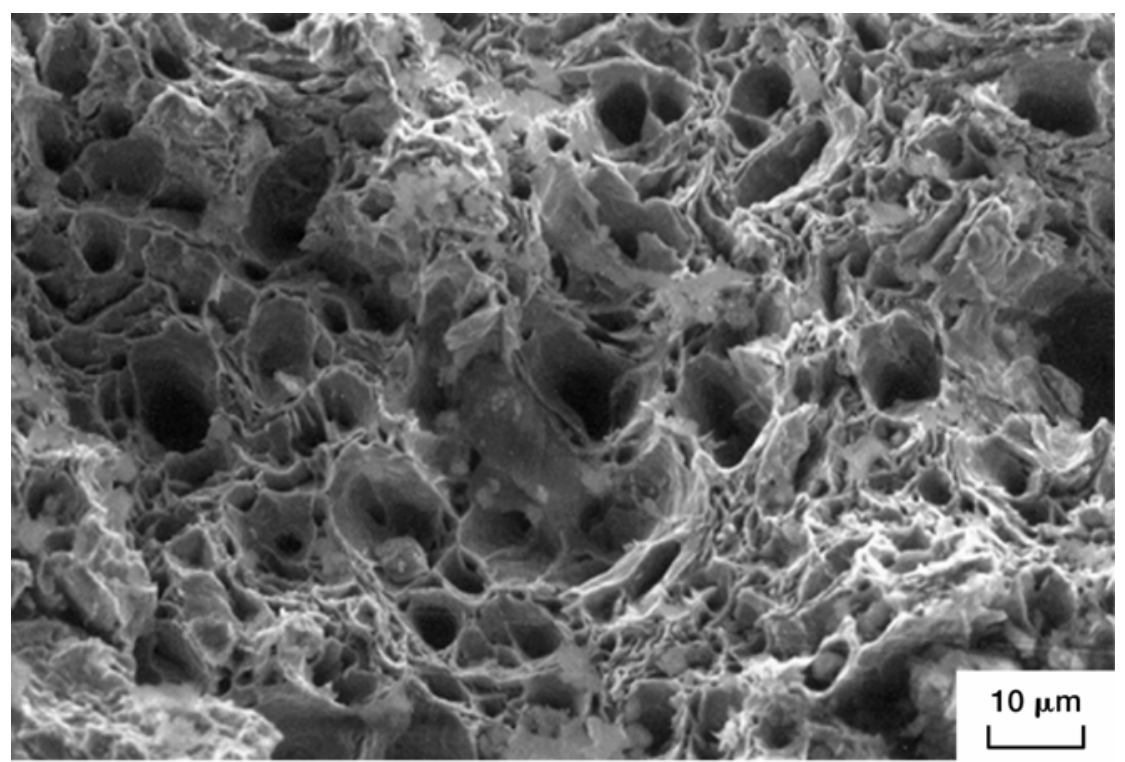

Figure 10.-Scanning electron micrograph of a specimen crept at $900 \mathrm{~K}$ under an initial applied stress of $80.2 \mathrm{MPa}$ with a fracture life of $9.9 \mathrm{~h}$ showing evidence of dimpled fracture. The photograph was obtained with the fracture surface tilted at $15^{\circ}$ to the electron beam direction.
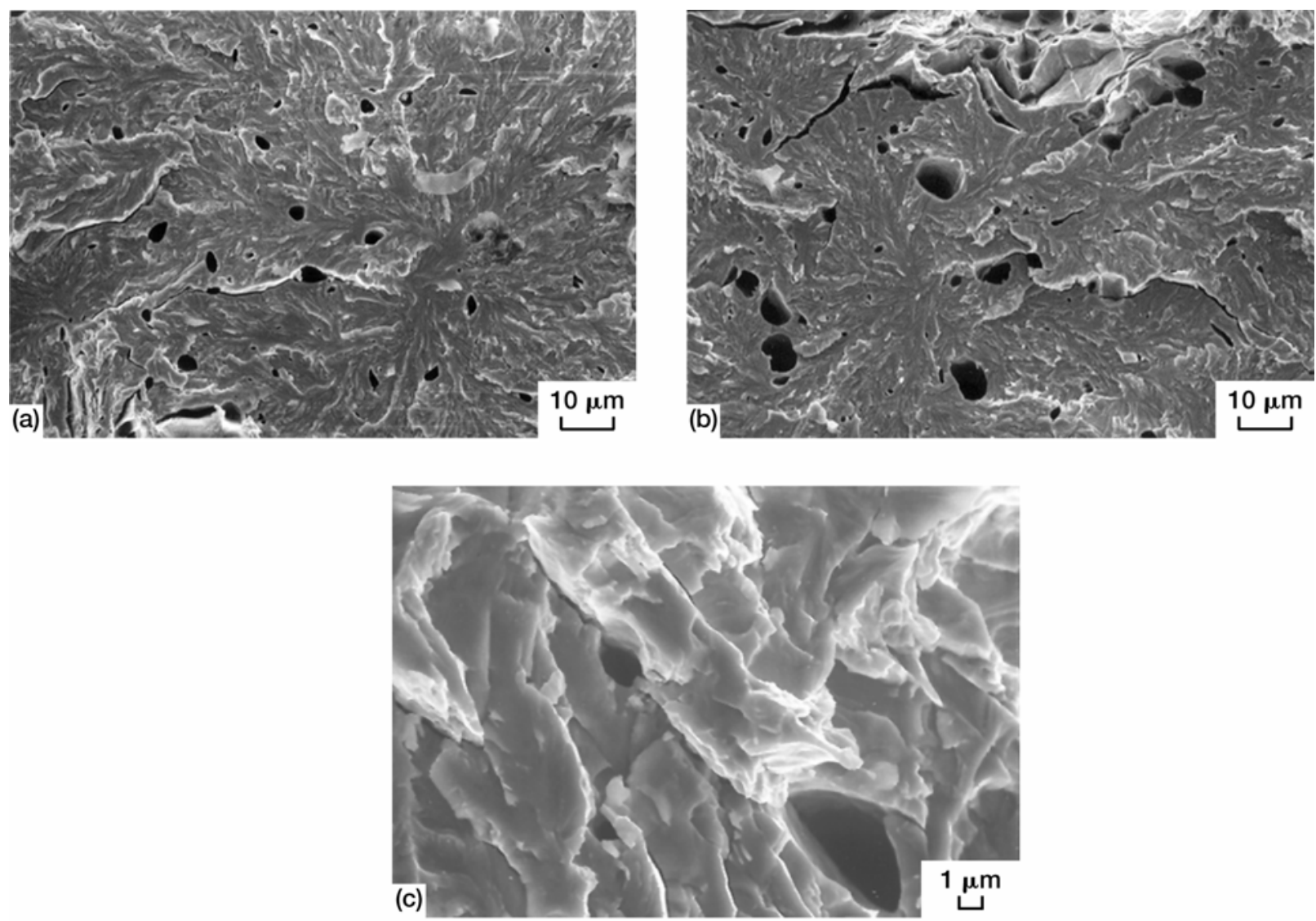

Figure 11.-Scanning electron micrographs of fracture surfaces of near-stoichiometric NiAl specimens crept to failure at 900 and $1000 \mathrm{~K}$ showing the presence of intergranular and transgranular voids. (a) $\mathrm{T}=1000 \mathrm{~K}$, $\mathrm{S}_{\mathrm{a}}=25 \mathrm{MPa}, \mathrm{t}_{\mathrm{f}}=1458.2 \mathrm{~h}$; (b) T $=900 \mathrm{~K}, \mathrm{~S}_{\mathrm{a}}=70 \mathrm{MPa}, \mathrm{t}_{\mathrm{f}}=41.2 \mathrm{~h}$; (c) $\mathrm{T}=1000 \mathrm{~K}, \mathrm{~S}_{\mathrm{a}}=65 \mathrm{MPa}, \mathrm{t}_{\mathrm{f}}=1.8 \mathrm{~h}$. All photographs were obtained under $0^{\circ}$ tilt conditions. 


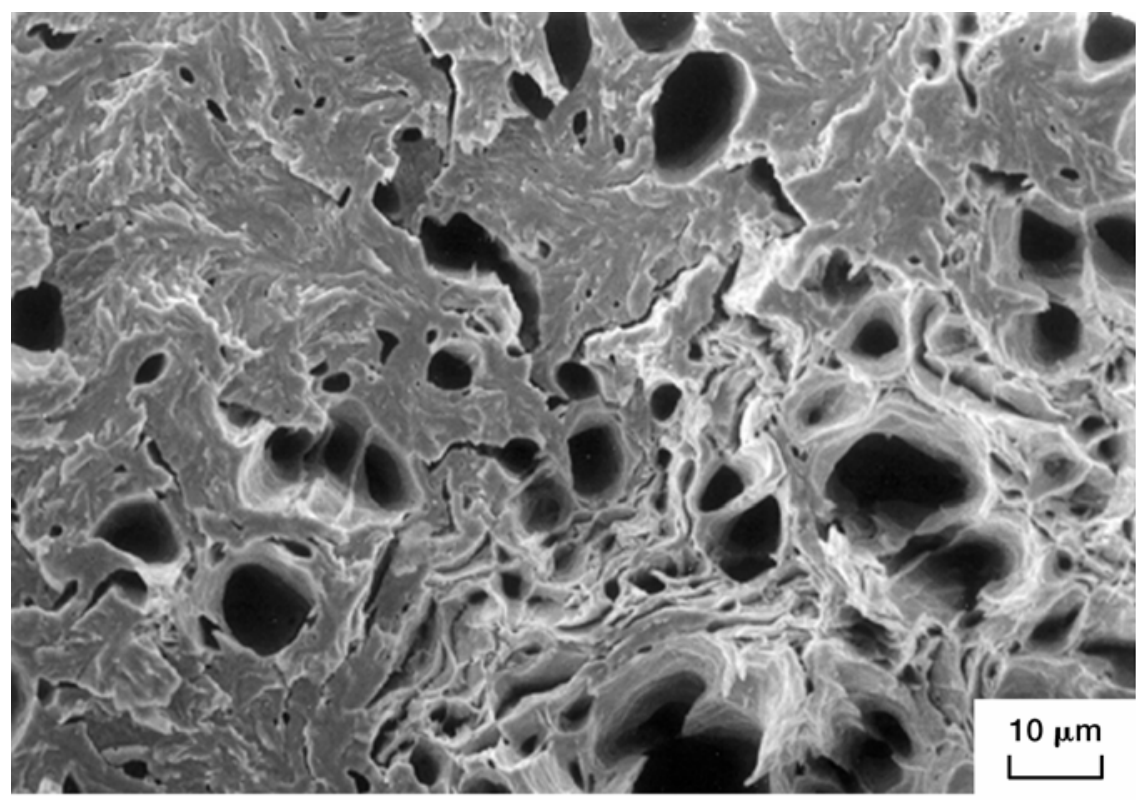

Figure 12.-Scanning electron micrograph of the fracture surface of a specimen crept at $1000 \mathrm{~K}$ under an initial applied stress of $25 \mathrm{MPa}$ with a fracture life of $1458.2 \mathrm{~h}$ showing evidence of void growth and coalescence. The photograph was obtained under a $0^{\circ}$ tilt condition.

A further transition in the fracture morphology was observed at $1000 \mathrm{~K}$ at an initial applied stress of $50 \mathrm{MPa}$ (fig. 7(h)) and between 1100 and $1200 \mathrm{~K}$ under applied stresses varying between 13 and $25 \mathrm{MPa}$ (figs. 7 (i)-(m)). These microstructures were indicative of plastic rupture similar to those described by Ashby et al. [28-32]. In extreme cases, these fracture surfaces either narrowed approximately to a point (fig. 13(a)) or a chisel edge (fig. 13(b)). The variation of the ratio of the maximum diameter, $D_{\max }$, to minimum diameter, $D_{\min }$, for specimens exhibiting chisel edge fracture varied between 3.7 and 19.5. Although all these specimens showed a dimpled fracture appearance at higher magnifications, it is noteworthy that specimens that exhibited a chisel fracture showed a large amount of inclusions associated within each void (fig. 13(c)). This observation is consistent with models proposed for plastic rupture [32]. Longitudinal sections of the specimens showed a general absence of voids far away from the fractured region although some grain boundary cavities were seen in a few samples.

In contrast, grain boundary cavities were observed at 1100 and $1200 \mathrm{~K}$ under an initial stress of $10 \mathrm{MPa}$ lying primarily transverse to the stress axis (figs. 14(a)-(c)). Most of these cavities were faceted although a few appeared to have developed rounded edges due to diffusion (fig. 14(c)). In general, the grain boundary cavities were isolated even after $9114 \mathrm{~h}$ although there was some limited evidence that cavity growth and interlinkage had occurred in few areas of the specimens. Interestingly, many of the grain boundaries are devoid of cavitation thereby suggesting that the extent of grain boundary sliding and vacancy condensation is relatively small under these conditions. 

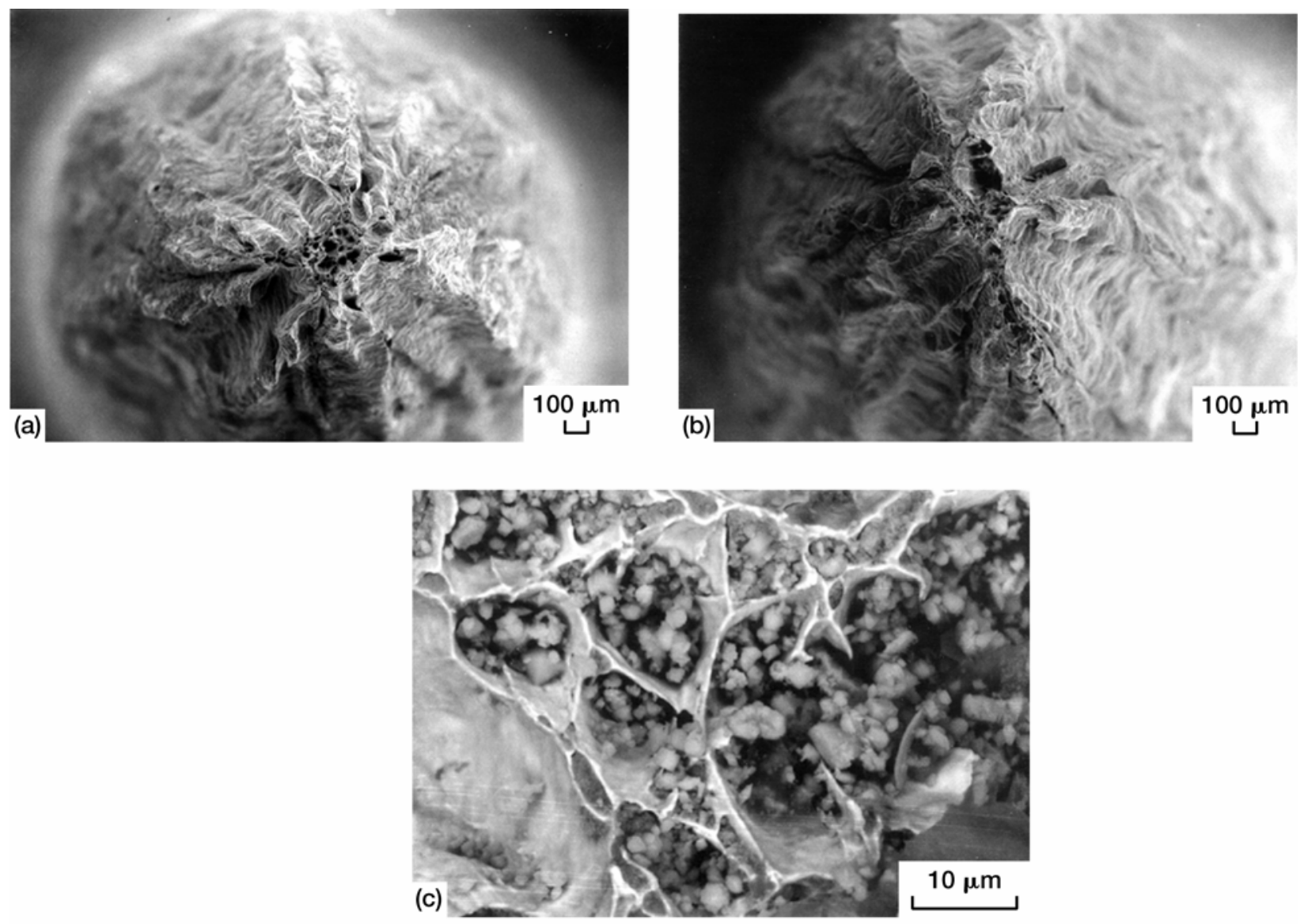

Figure 13.-Scanning electron micrographs of the fracture surfaces of specimens crept at $1200 \mathrm{~K}$ showing examples of external necking to (a) an approximate point under an initial applied stress of $15 \mathrm{MPa}$ after a fracture life of $199.4 \mathrm{~h}$ and (b) a chisel edge under an initial applied stress of $20 \mathrm{MPa}$ after a fracture life of $26.5 \mathrm{~h}$. Both photographs were obtained under $0^{\circ}$ tilt conditions. (c) Back scattered image of the fracture surface of the specimen shown in (b) under a $10^{\circ}$ tilt condition revealing the presence of inclusions in the voids. 

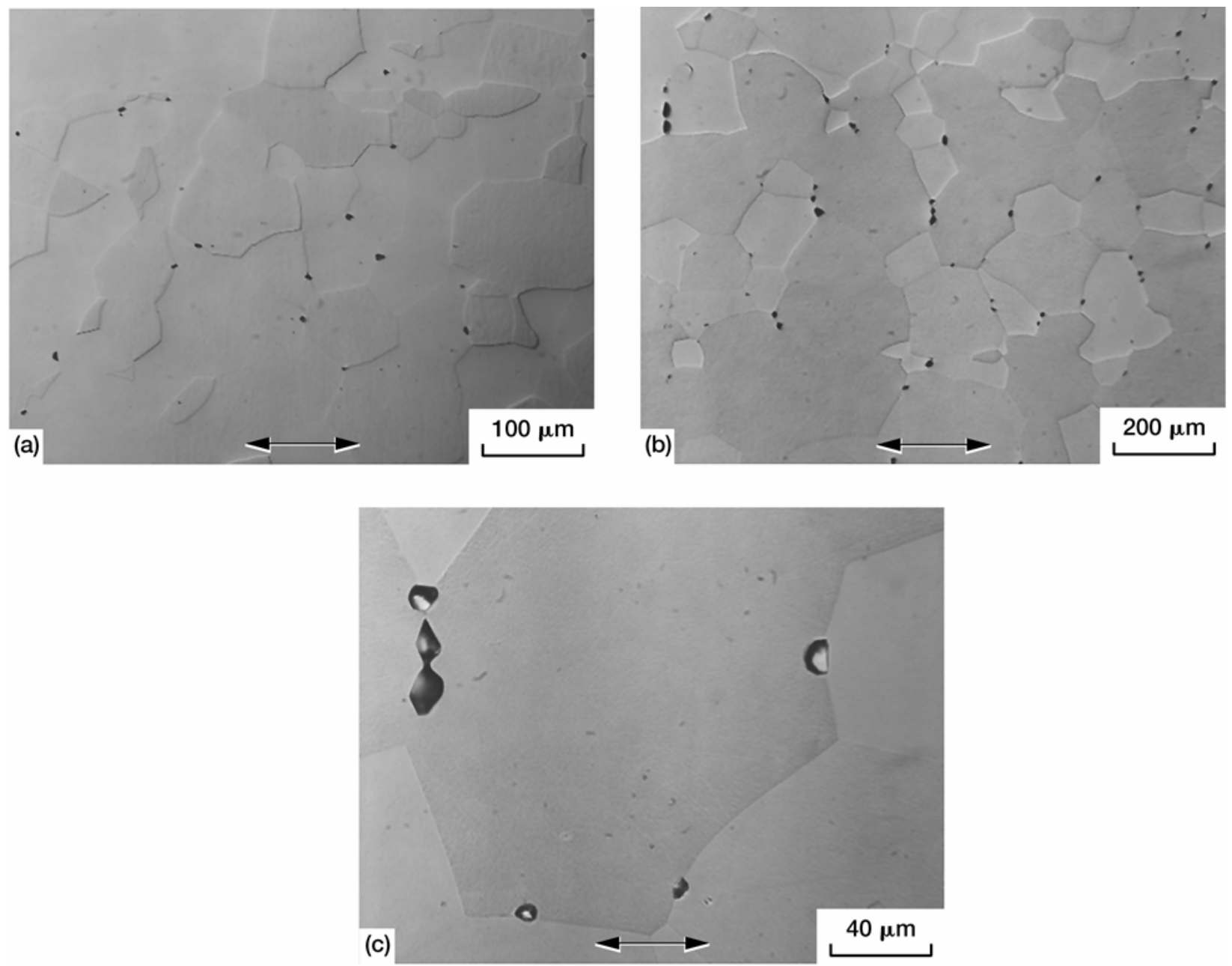

Figure 14.-Optical micrographs of the as-polished longitudinal sections of specimens crept at (a) $1100 \mathrm{~K}$ for $6693.5 \mathrm{~h}$ and (b) and (c) $1200 \mathrm{~K}$ for $9114.2 \mathrm{~h}$ under an initial applied stress of $10 \mathrm{MPa}$ showing the presence of faceted creep cavities mainly on grain boundaries transverse to the stress axis. The arrows denote the stress axes. Evidence of void growth and coalescence is shown in (c). 


\section{Discussion}

\section{Effect of Creep on Creep Fracture}

The stress and temperature dependence of $t_{f}$ shown in figures 1 and 2 suggest that creep fracture in $\mathrm{NiAl}$ is a thermally activated process with an activation energy of about $250 \mathrm{~kJ} \mathrm{~mol}^{-1}$ (fig. 3). In general, the tabulated values of the creep [18] and fracture stress exponents given in table 2 are in qualitative agreement with each other. Clearly, the fracture behavior of NiAl is influenced by creep as confirmed by figures 4(a) and (b) and equation (4a) to (4c) under the stress and temperature conditions studied in this investigation. This observation would suggest that $Q_{f}$ should approximately equal $Q_{c}$ in the previously identified four creep regimes [18]. As shown in figure 3, the values of $Q_{f}$ correspond predominantly to creep regimes II and III so that valid comparisons between the magnitudes of $Q_{c}$ and $Q_{f}$ can be made only for these two regions. The values of $Q_{c}$ and $Q_{f}$ are similar in creep regime III with the average magnitude of $Q_{c} / Q_{f} \sim 1$.

In contrast, the magnitude of $Q_{f}$ is less than $Q_{c}$ by about $150 \mathrm{~kJ} \mathrm{~mol}^{-1}$ in region II with the ratio $Q_{c} / Q_{f}$ being as high as 1.8 (fig. 3). In principle, this discrepancy can be qualitatively rationalized if diffusion either along the grain boundaries or along the internal surfaces of nucleated cavities also influences creep fracture. Although the intergranular cavity growth models proposed by Hull and Rimmer [36] and Chuang et al. [37] involve grain boundary and surface diffusion, respectively, it is unlikely that these mechanisms are applicable in the present instance for two reasons. First, the observed values of $q>3$ (table 2) do not agree with the predicted values of 1 and 3 for the mechanisms proposed by Hull and Rimmer [36] and Chuang et al. [37], respectively. Second, as discussed earlier, intergranular cavitation was observed in only two specimens, whereas other specimens failed by other modes of fracture. Thus, these creep cavity growth models are insufficient to account for this discrepancy. At present, the reason for this significant difference between $Q_{c}$ and $Q_{f}$ in regime II is unclear.

\section{Experimental Fracture Mechanism Map}

The fracture microstructures shown in figures 7 to 14 are summarized in an experimental fracture mechanism map, where the data are plotted in $S_{a}-T$ space (fig. 15). The different fracture mechanisms and the limitations of fracture mechanism maps are described elsewhere [29-31]. The positions of the boundaries shown in figure 15 are approximate and they are represented by broken lines. In reality, their widths are much broader than shown in the figure since mixed failure modes were often observed. The fracture microstructures of Raj et al. [38,39] obtained on powder-metallurgy (PM) extruded NiAl are also included in figure 15 in order to extend the range of observations to room temperature. The fracture microstructures of cast and $\mathrm{PM} \mathrm{NiAl}$ are generally similar although it is expected that the positions of the boundaries are likely to be different. Despite these limitations, figure 15 gives a good overview of the different fracture mechanisms and their relation to each other in stress-temperature space, which provide important insights in engineering design. 


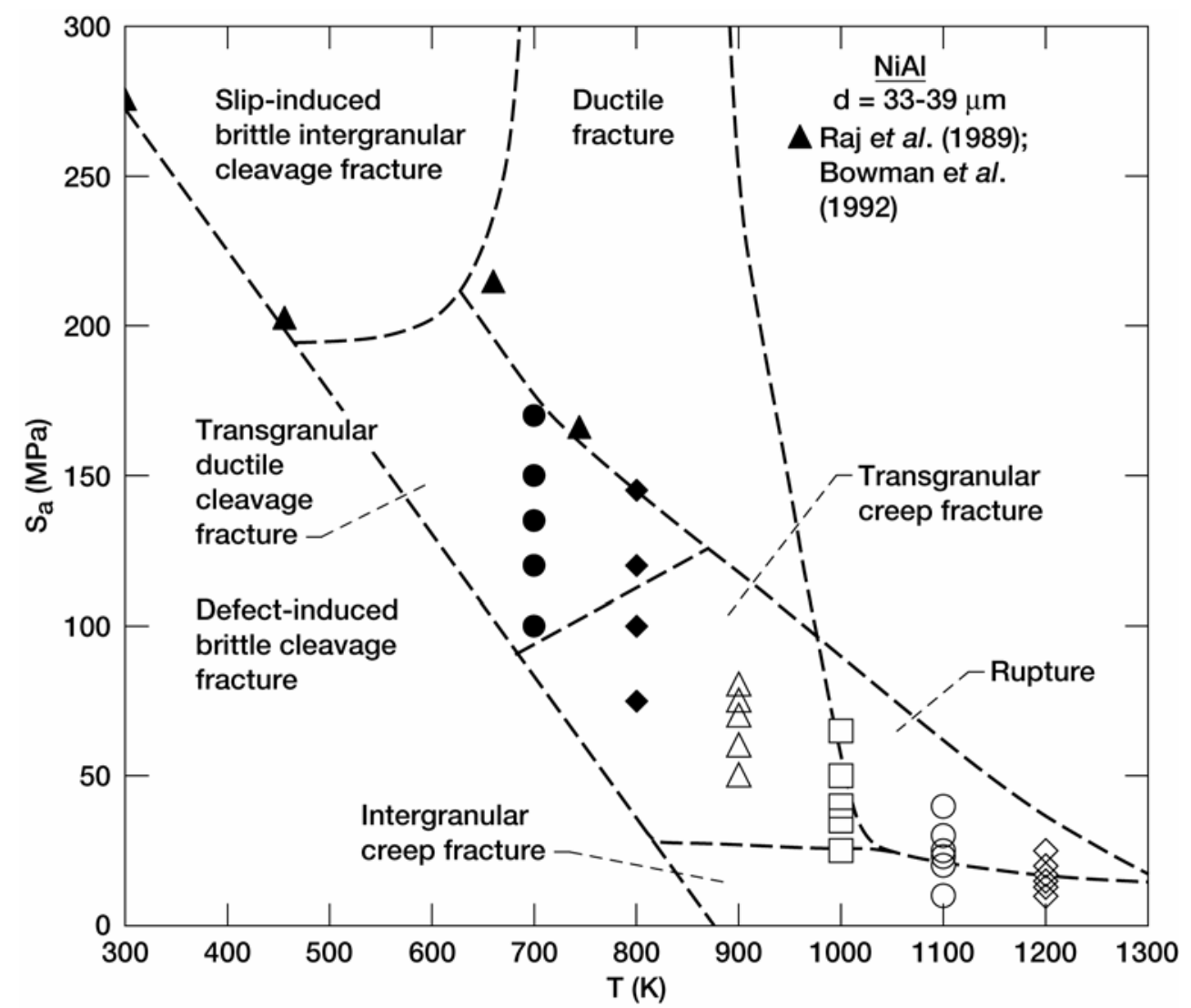

Figure 15.-Experimental fracture map plotted as the initial applied stress against absolute temperature for cast and extruded near-stoichiometric NiAl based on the present fracture observations. The observations of Raj et al. [38, 39] on powder metallurgy $\mathrm{NiAl}$ are also shown in the figure.

Following Ashby et al. [28-31], three types of cleavage fracture mechanisms are identified in figure 15. Defect-induced brittle cleavage fracture occurs when pre-existing cracks in the material propagate when the fracture stress, $\sigma_{f}$, reaches the Griffith criterion in the elastic region. In this case

$$
\sigma_{f}=\left(\frac{E G_{C}}{\pi a}\right)^{0.5}
$$

where $G_{c}$ is the fracture toughness and $\pi a$ is the length of the pre-existing defect. Slip-induced brittle intergranular cleavage fracture is preceded by limited plasticity that results in the nucleation of cracks at grain boundaries due to the availability of limited slip systems. Failure occurs due to the propagation of these grain boundary cracks. In this case, $\sigma_{f}$ has a similar form as equation (5) except that it now scales with grain size instead of the size of the pre-existing defect [29]. As demonstrated in previous investigations [38,39], near-stoichiometric NiAl exhibits only limited ductility, typically much less than $1 \%$, and fails predominantly by brittle intergranular cleavage fracture below the ductile-to-brittle transition temperature (DBTT). The two low temperature datum points have been inserted in the slipinduced brittle intergranular cleavage fracture regime in figure 15. In the absence of additional data, the boundary between this region and the defect-induced brittle cleavage fracture regime has been demarcated by extending the line joining these datum points to zero stress. Transgranular ductile cleavage 
fracture is observed in NiAl at higher temperatures, where fracture is preceded by significant plasticity (figs. 7(a)-(d) and fig. 8).

Under favorable stress and temperature conditions when cleavage fracture is suppressed, NiAl exhibits the classical cup and cone morphology ductile fracture and this region is termed as "ductile fracture" in figure 15. In this case, fracture involves the nucleation, plastic growth and coalescence of voids without significant creep. Ductile fracture was observed in NiAl above the DBTT and a single datum point corresponding to the ductile fracture regime is shown in figure 15 [38,39]. Similar fracture morphologies observed under creep conditions are distinguished as transgranular creep fracture in figure 15 due to the fact that diffusional processes help reduce stress concentration at inclusions in the material thereby postponing the advent of void nucleation. These cup and cone fractures are evident in figures $7(\mathrm{e})$ to $(\mathrm{g})$ and they are complimented by the dimpled fracture morphologies shown in figure 10 and to some extent in figure 12. Alumina inclusions, which are often observed in extruded NiAl especially when processed by powder metallurgy techniques, are likely to influence void nucleation in this material under these stress and temperature conditions.

The formation of intergranular voids similar to those observed in pure metals and solid solution alloys [25] are observed in NiAl at and above $1100 \mathrm{~K}$ below stresses of $10 \mathrm{MPa}$ (figs. 14(a)-(c)). Even in this case, many of the grain boundaries were devoid of voids thereby suggesting difficulty in cavity nucleation. Instead, rupture is observed at high temperatures with the suppression of other failure modes (figs. 7(i)-(m) and figs. 13(a)-(b)). The approximate boundaries of these fracture regions are mapped in figure 15.

\section{Summary and Conclusions}

Tensile creep fracture data on polycrystalline near stoichiometric-NiAl were obtained between 700 and $1200 \mathrm{~K}$ under initial applied stresses varying between 10 and $200 \mathrm{MPa}$. The stress exponents for creep fracture varied between 5.0 and 10.7. The activation energy for fracture was about $250 \mathrm{~kJ} \mathrm{~mol}^{-1}$. The fracture lives exhibited an inverse dependence on the secondary creep rate given by equations 4(a) to (c). Typically, the Monkman-Grant constants varied between 0.01 and 0.45 similar to values reported for pure metals and alloys.

Extensive microstructural observations were conducted on fractured and unbroken specimens in order to identify the predominant mode of failure. Typically, these observations revealed that the specimens were generally devoid of cracks and voids far away from the fracture zone. Four different fracture morphologies were observed for the range of stresses and temperatures studied in this investigation. These include transgranular ductile cleavage fracture, transgranular creep fracture, intergranular creep fracture and rupture. These microstructural observations are summarized in an experimental fracture map in a manner similar to those constructed by Ashby and co-workers for other materials [28-31]. The map provides an insightful overview of the different failure modes observed in polycrystalline nearstoichiometric NiAl with grain sizes varying between 30 and $40 \mu \mathrm{m}$ under stress and temperature conditions typical of most engineering applications. 


\section{References}

1. R.R. Vandervoort, A.K. Mukherjee and J.E. Dorn: Trans. ASM, 1966, vol. 59, pp. 930-44.

2. J.D. Whittenberger: J. Mater. Sci., 1987, vol. 22, pp. 394-402.

3. J.D. Whittenberger: J. Mater. Sci., 1988, vol. 23, pp. 235-240.

4. J.D. Whittenberger: Effect of Grain Size on the High Temperature Properties of B2 Aluminides, NASA TM-101382, Lewis Research Center, Cleveland, OH, 1987.

5. K. Xu and R.J. Arsenault: Acta Material, 1999, vol. 47, pp. 3023-3040.

6. W. Yang, R.A. Dodd and P.R. Strutt: Metall. Trans., 1972, vol. 3, pp. 2049-2054.

7. W.J. Yang and R.A. Dodd: Met. Sci. J., 1973, vol. 7, pp. 41-47.

8. P.R. Strutt, R.S. Polvani and B.H. Kear: Scripta Metall., 1973, vol. 7, pp. 949-954.

9. A. Prakash and R.A. Dodd: J. Mater. Sci., 1981, vol. 16, 2495-2500.

10. M. Rudy and G. Sauthoff: Mater. Sci. Eng., 1986, vol. 81, 525-30.

11. S.V. Raj and S.C. Farmer: in High-Temperature Ordered Intermetallic Alloys V, I. Baker, R. Darolia, J. D. Whittenberger and M.H. Yoo, eds., Materials Research Society, Pittsburgh, PA, 1993, vol. 288, pp. 647-652.

12. K. Sadananda, C.R. Feng, H.N. Jones and J.J. Petrovic: in Proceeding of the First International Symposium on Structural Intermetallics, R. Darolia, J.J. Lewandowski, C.T. Liu, P.L. Martin, D.B. Miracle and M.V. Nathal, eds., The Minerals, Metals and Materials Society, Warrendale, PA, 1993, pp. 809-818.

13. S.V. Raj and S.C. Farmer: Metall. Mater. Trans. A, 1995, vol. 26A, pp. 343-356.

14. E. Artz and P. Grahle: in High-Temperature Ordered Intermetallic Alloys VI, J. Horton, I. Baker, S. Hanada, R.D. Noebe and D.S. Schwartz, eds., Materials Research Society, Pittsburgh, PA, 1995, vol. 364, pp. 525-536..

15. S.V. Raj, A. Garg and T.R. Bieler: in High-Temperature Ordered Intermetallic Alloys VII, C.C. Koch, C.T. Liu, N.S. Stoloff and A. Wanner, eds., Materials Research Society, Pittsburgh, PA, 1997, vol. 460, pp. 473-478.

16. E. Artz and P. Grahle: Acta Material, 1998, vol. 46, pp. 2717-2727.

17. T.A. Venkatesh and D.C. Dunand: Metall. Mater. Trans. A, 2000, vol. 31A, pp. 781-792.

18. S.V. Raj, Mater. Sci. Eng. A, 2003, vol. A356, pp. 283-297.

19. M.R. Harmouche and A. Wolfenden: J. Testing. Eval., 1987, vol. 15, pp. 101-04.

20. G.F. Hancock and B.R. McDonnell: Phys. Status Solidi, 1971, vol. 4(a), pp. 143-50.

21. St. Frank, S.V. Divinski, U. Södervall and Chr. Herzig: Acta Material, 2001, vol. 49, pp. 1399-1411.

22. F.C. Monkman and N.J. Grant: Proc. ASTM, 1956, vol. 56, pp. 593-605.

23. F. Dobeš and K. Milička: Metal Sci., 1976, vol. 10, pp. 382-384.

24. G.H. Edward and M.F. Ashby: Acta Metall., 1979, vol. 27, pp. 1505-1518.

25. S.V. Raj: High Temperature Creep, Grain Boundary Sliding and Fracture Studies on Copper and Alpha Brass, Ph.D. Thesis, University of Southern California, Los Angeles, CA, 1984.

26. G.W. Greenwood: Phil. Trans. R. Soc. Lond. A, 1978, vol. 288, pp. 213-227.

27. W. Pavinich and R. Raj: Metall. Trans. A, 1977, vol. 8A, pp. 1917-1933.

28. M.F. Ashby: Fracture-1977, ICF 4, Advances in Research on the Strength and Fracture of Materials (ed. D.M.R. Taplin) 1978, vol. 1, pp. 1-14.

29. C. Gandhi and M.F. Ashby: Acta Metall., 1979, vol. 27, pp. 1565-1602.

30. C. Gandhi, M.F. Ashby and D.M.R. Taplin: The Development of a Fracture Mechanism Map for Pure Nickel Tested in Simple Tension, CUED/C/MATS/TR.35, University of Cambridge, Cambridge, UK, 1977.

31. M.F. Ashby, C. Gandhi, and D.M.R. Taplin: Acta Metall., 1979, vol. 27, pp. 699-729.

32. D. Teirlinck, F. Zok, J.D. Embury and M.F. Asbhy: Acta Metall., 1988, vol. 36, 1213-1228.

33. C. Gandhi, M.F. Ashby and D.M.R. Taplin: The Development of a Fracture Mechanism Map for Pure Nickel Tested in Simple Tension, CUED/C/MATS/TR.35, University of Cambridge, Cambridge, UK, 1977. 
34. M.F. Ashby, C. Gandhi, and D.M.R. Taplin: Acta Metall., 1979, vol. 27, pp. 699-729.

35. D. Teirlinck, F. Zok, J.D. Embury and M.F. Asbhy: Acta Metall., 1988, vol. 36, pp. 1213-1228.

36. D. Hull and D.E. Rimmer: Philos. Mag., 1959, vol. 4, pp. 673-687.

37. T. Chuang, K.I. Kagawa, J.R. Rice, and L.B. Sills: Acta Metall., 1979, vol. 27, pp. 265-284.

38. S.V. Raj, R.D. Noebe. and R. Bowman: Scripta Metall., 1989, vol. 23, pp. 2049-2054.

39. R.R. Bowman, R.D. Noebe, S.V. Raj and I.E. Locci: Metal. Trans. A, 1992, vol. 23A, pp. 1493-1508. 


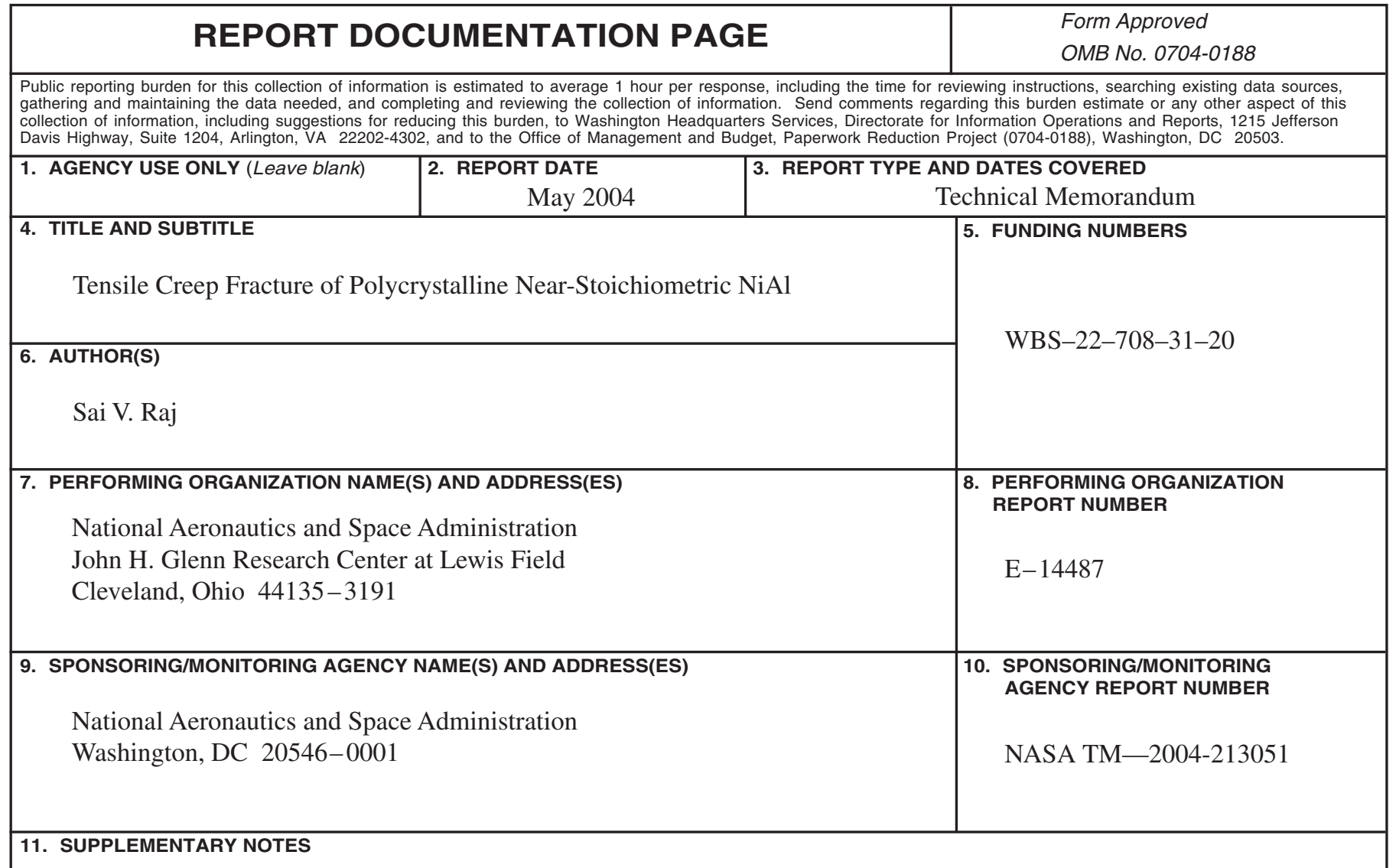

Responsible person, Sai V. Raj, organization code 5160, 216-433-8195.

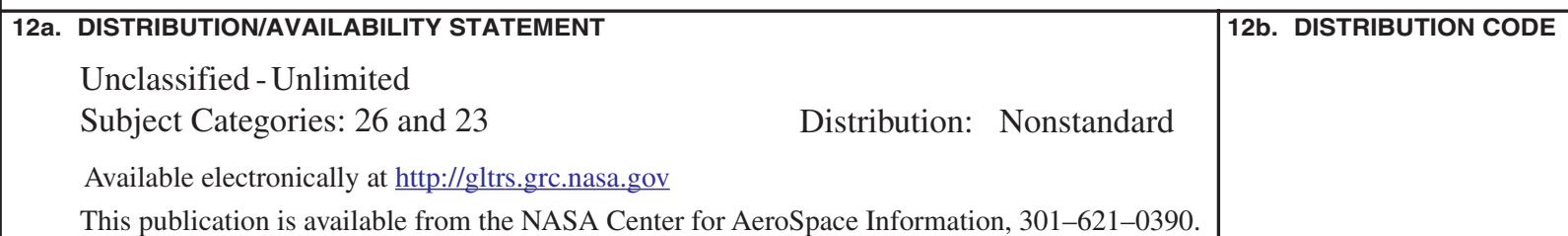

13. ABSTRACT (Maximum 200 words)

Tensile creep fracture behavior of polycrystalline near-stoichiometric NiAl has been studied between 700 and $1200 \mathrm{~K}$ under initial applied stresses varying between 10 and $200 \mathrm{MPa}$. The stress exponent for fracture varied between 5.0 and 10.7 while the activation energy for fracture was $250 \pm 22 \mathrm{~kJ} \mathrm{~mol}^{-1}$. The fracture life was inversely proportional to the secondary creep rate in accordance with the Monkman-Grant relation although there was extensive scatter in the data. This observation suggests that the fracture life for near-stoichiometric NiAl was influenced by creep under these stress and temperature conditions. Several different fracture morphologies were observed. Transgranular ductile cleavage fracture occurs at $700 \mathrm{~K}$ and at the higher stresses at $800 \mathrm{~K}$. The fracture mode transitions to transgranular creep fracture at 900 and $1000 \mathrm{~K}$ and at lower stresses at $800 \mathrm{~K}$, while plastic rupture and grain boundary cavitation occur at 1100 and $1200 \mathrm{~K}$. An experimental fracture mechanism map is constructed for near-stoichiometric NiAl.

\begin{tabular}{|c|c|c|c|}
\hline \multicolumn{3}{|l|}{ 14. SUBJECT TERMS } & 15. NUMBER OF PAGES \\
\hline \multicolumn{3}{|c|}{$\begin{array}{l}\text { Creep fracture; NiAl; Nickel aluminide; Fracture life; Fracture machanism map; Rupture } \\
\text { life; Cleavage; Voids }\end{array}$} & 25 \\
\hline Unclassified & Unclassified & Unclassified & \\
\hline \multicolumn{3}{|l|}{ NSN 7540-01-280-5500 } & ndard Form 298 (Rev. 2-89) \\
\hline
\end{tabular}



